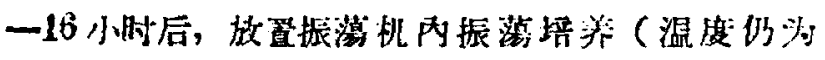

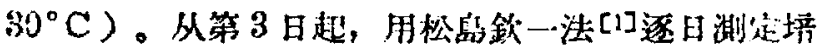

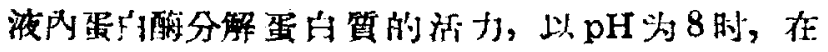

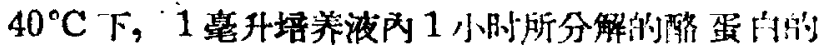
毫克数，作为蛋白酸活力的单位。

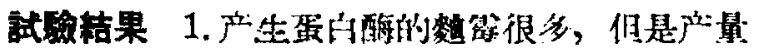

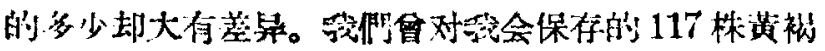

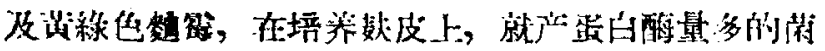

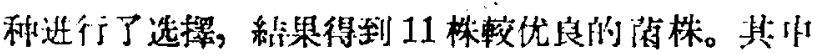

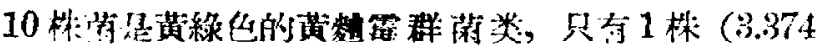

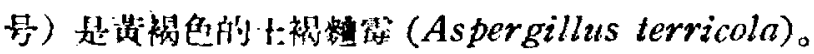

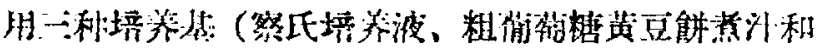

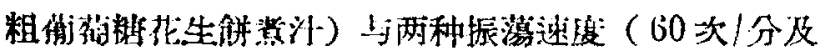

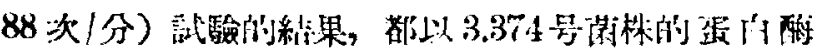

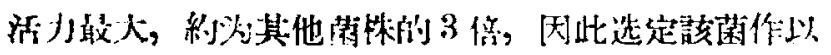

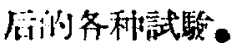

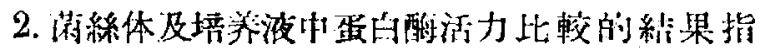

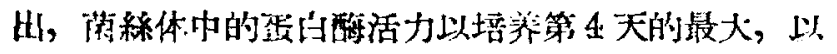

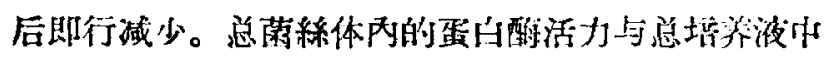

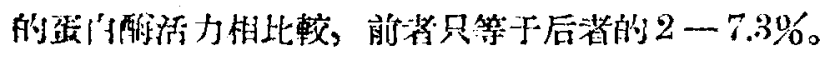

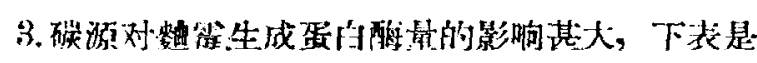

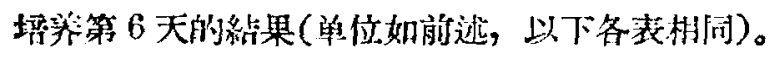

\begin{tabular}{|c|c|c|c|c|c|c|c|c|c|c|c|c|}
\hline 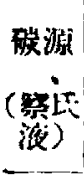 & 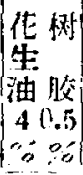 & 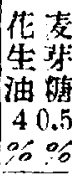 & $\begin{array}{l}\text { 化 } \\
\text { 生 } \\
\text { 油 } \\
4 \%\end{array}$ & $\begin{array}{l}\text { 油 } \\
\text { 酸 } \\
4 \%: 0\end{array}$ & 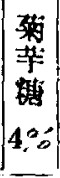 & $\left\{\begin{array}{l}\text { 吾 } \\
\text { 碳 } \\
4 \% \\
4 \%\end{array}\right.$ & $\begin{array}{l}H \\
\text { 温 } \\
4: 0\end{array}$ & 旅 & $\left\{\begin{array}{l}\text { 树 } \\
\text { 胶 } \\
5 \% \text { 。 }\end{array}\right.$ & 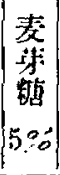 & 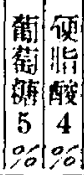 & 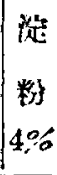 \\
\hline 蛋当㩆 & 400 & 400 & 333 & & 240 & 172 & 150 & 120 & 120 & & 25 & 100 \\
\hline
\end{tabular}

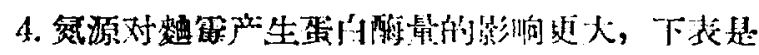

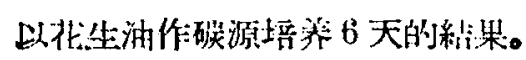

\begin{tabular}{|c|c|c|c|c|c|c|c|c|c|}
\hline 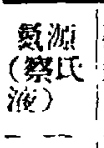 & 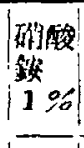 & 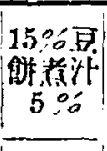 & 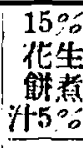 & $\begin{array}{l}\text { 碓酸 } \\
\text { 的 } \\
1.5 \circ \%\end{array}$ & $\begin{array}{l}\text { 楚白 } \\
\text { 膊 } \\
2.0 \%\end{array}$ & $\begin{array}{l}\text { 繁 } \\
\text { 䨛 } \\
2.0 \%\end{array}$ & 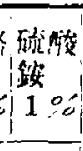 & & 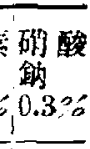 \\
\hline $\begin{array}{c}\text { 棸白醮 } \\
\text { 活力 }\end{array}$ & 400 & 333 & 250 & 72 & 20 & 15 & 0 & 0 & 400 \\
\hline
\end{tabular}

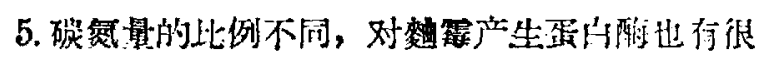
大的影响，下表所列的是第 6 天的結果。

\begin{tabular}{|c|c|c|c|c|c|c|c|c|c|c|c|}
\hline 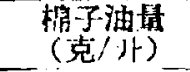 & 15 & 20 & 25 & 30 & 40 & 40 & 40 & 40 & 40 & 40 & 40 \\
\hline 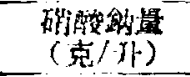 & 2.5 & 2. & 2.5 & $2.5 \mid$ & 2.5 & 1.5 & 2.0 & 2.5 & 3.0 & 3.5 & 4.0 \\
\hline 盆白酮活力 & 300 & 400 & 400 & 400 & 400 & 12 & 240 & 400 & 400 & 250 & 250 \\
\hline
\end{tabular}

6. 了解到在酸性培养液內，生长的土被数管的管 白褐的活力甚小，中性培济液较为合适。有些碳源琙视

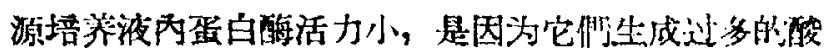

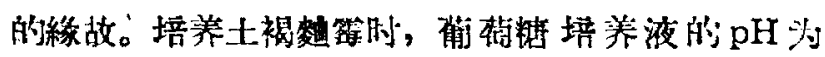
$5.08-5.13$ 时，蛋白酶的活力較小，的酸湲，氮化魰

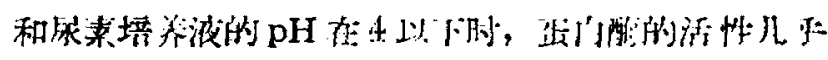

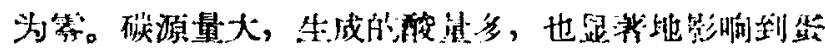
白酶活性的降低。

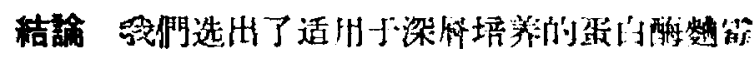

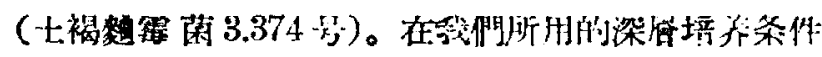

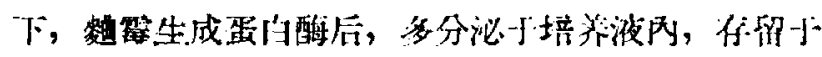

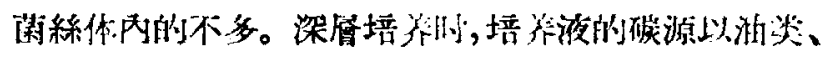

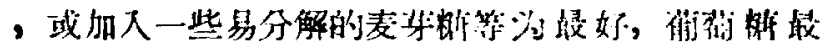

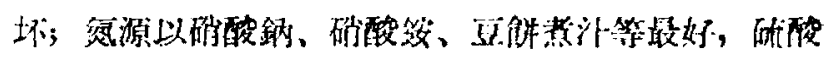

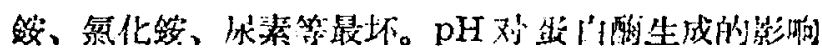

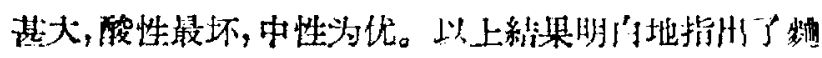

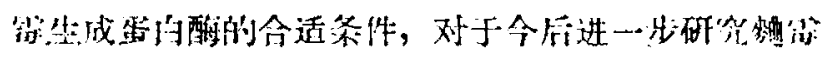

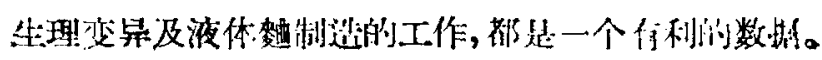

$$
\begin{aligned}
& \text { 㔨永闌 方心芳 严自正 }
\end{aligned}
$$

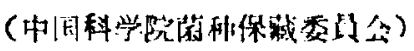

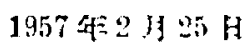

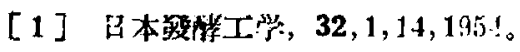

\section{徽生物利用 $\mathbf{N}$ - 磷酸苯丙 氨酸的試驗}

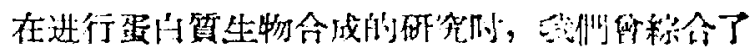

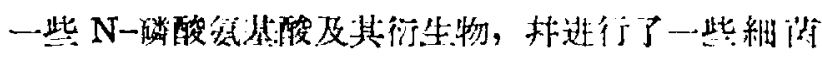

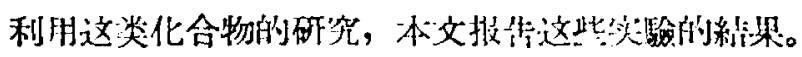

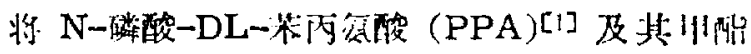

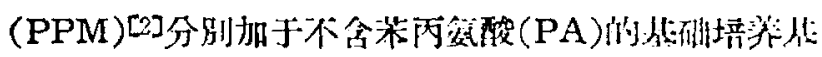

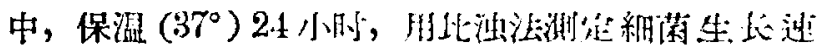
度, 綃果發現: Lactobacillus arabinosus 17-5 利

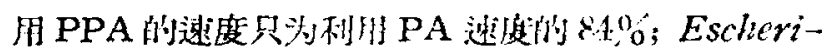

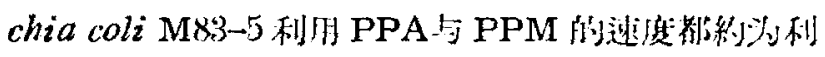
用PA的 60\%。这个秥果1;

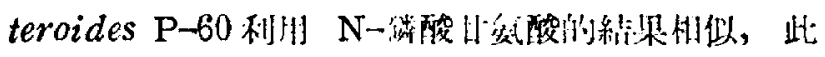

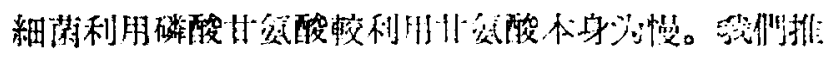

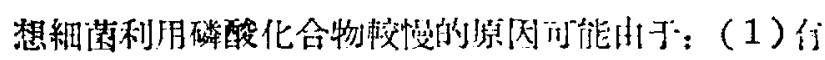
机磷化合物淩透細胞膜的能力較小[1]，风此进入彩胞 的速度也較慢; 或 (2) N-碳酸化合物必须尖經边磷

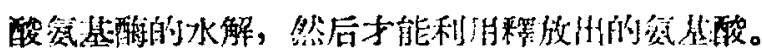

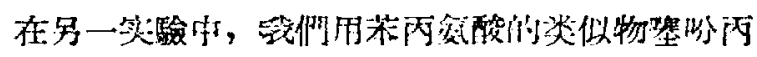

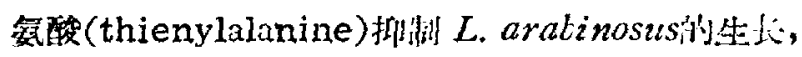

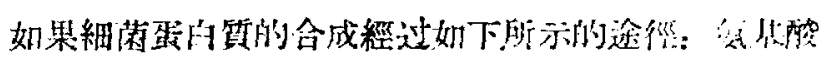

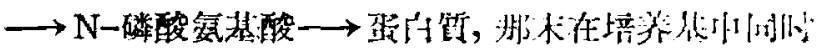

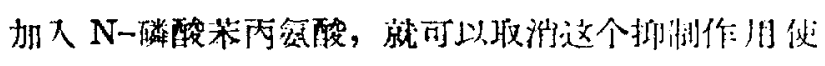

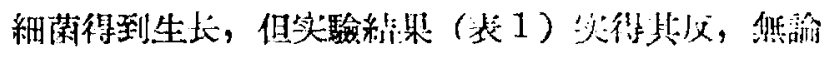

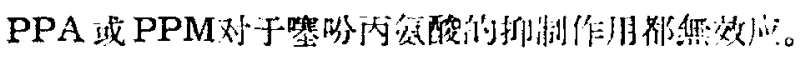

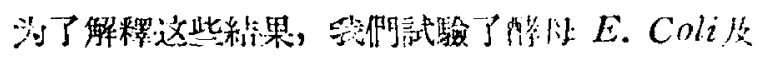

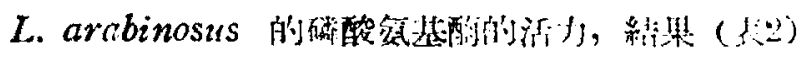




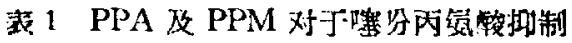

L. ardbinosus 17-5 生长的效应

\begin{tabular}{|c|c|c|c|c|c|c|}
\hline \multirow{3}{*}{ 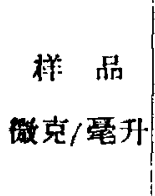 } & \multicolumn{6}{|c|}{ 比浊計掼 数 } \\
\hline & \multicolumn{3}{|c|}{ 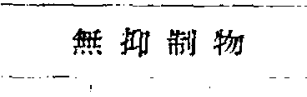 } & \multicolumn{3}{|c|}{ 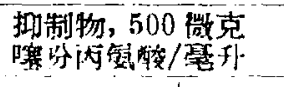 } \\
\hline & PA & PPA & $\mathrm{P}-\mathrm{M}$ & $\mathrm{P} A$ & PPA & PPM \\
\hline 0 & 2.5 & 2.5 & 2.5 & 2.5 & 2.5 & 2.5 \\
\hline 2.5 & 18.5 & 22.5 & 17.5 & 3.0 & 3.6 & 3.0 \\
\hline 5.0 & 28.5 & 34.0 & $2(1.5)$ & 4.3 & 4.7 & 3.5 \\
\hline 7.5 & 35.5 & 41.0 & 33.5 & 6.0 & 8.0 & 4.3 \\
\hline 10.0 & 38.5 & 42.5 & 38.0 & 9.0 & 12.5 & 4.7 \\
\hline
\end{tabular}

Henderson 同 Snell 楁基[0]。

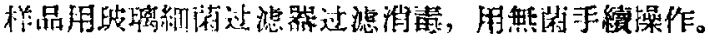

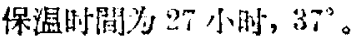

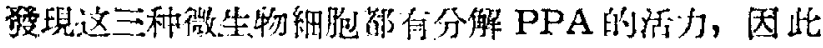

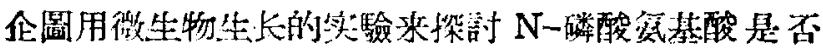
创含在蛋当算合成中的閏題是比較团焳的。

䒾 2 微生物对 PPA 的水解

\begin{tabular}{|c|c|c|c|}
\hline 时 間 & \multicolumn{3}{|c|}{ 水 } \\
\hline (小时) & 醀田 & E. Coli & L. arabinosus \\
\hline 12 & 14.9 & 12.7 & 4.69 \\
\hline 24 & 25.4 & 17.7 & 7.61 \\
\hline 48 & 47.0 & 22.2 & 8.62 \\
\hline
\end{tabular}

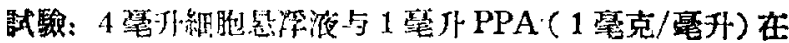

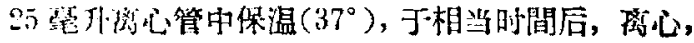

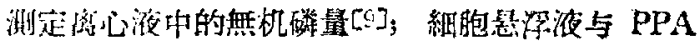

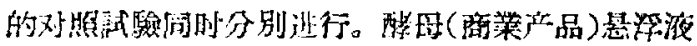

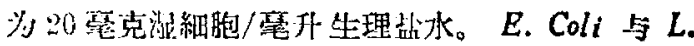

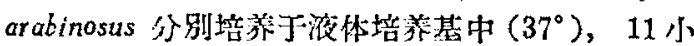

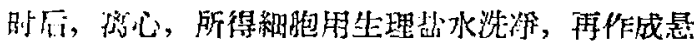

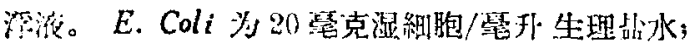
L. arabinosus 为 1 笔克/菖刑。

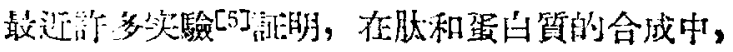

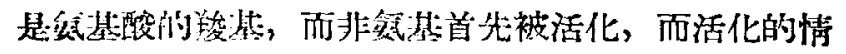

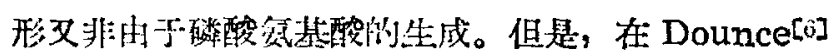

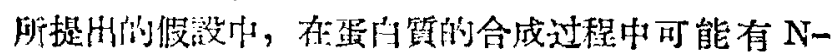

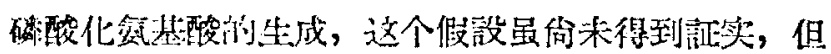

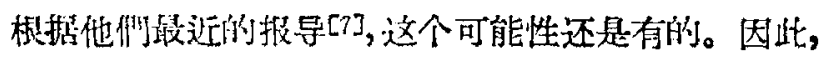
$\mathrm{N}$ 一磷隔基酸及其衍生物是否与蛋白算生物合成有

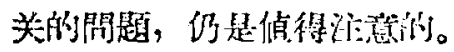

$$
\text { 李 士 臎 }
$$

(虾国医学科学院生物化学系)

$$
1957 \text { 程 } 3 \text { 月 } 6 \text { 日 }
$$

附繁：本笑歌是在美国 Texas 大学瑚所作，承 R. E. Eakin

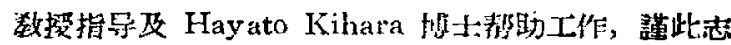
瑾。

[1] S. O. Li and R. F. Eakin, J. Am. Chem. Soc., 77, 1860 (1955).
[2] S. O. L:, is:d, :4, 5959(1932).

[3] G. Agren, Acta Chem. Scand, 8, 705 (1954).

[4] J. Wittenberg and A. Kornberg, J. Biol. Chem.. 2:2, 431 (1953).

[5] H. Borsook, Proc. third Internat Cong. Biochem., p. (2, 1956, Acsdemy Press Inc., New York.

[6] A. L. Dounce, Enzymologia, 15, 251 (1952).

[7] J. L. Potter and A. L. Douncs, J. Am. Chem. Soc., 78, 3078 (1956).

[8] L. M. Henderson and E. E. Snell, J. Biol. Chem., 172, 15 (1948).

[9] O. H. Lowry and J. A. Lopez, ibid, 162, 421 (1946).

\section{新疆蝗虫地理的研究}

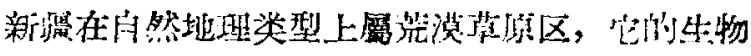

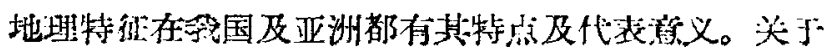

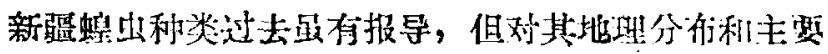

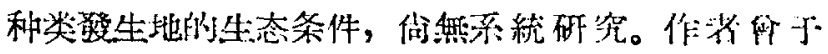

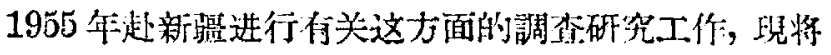
所得初步絬果简要报导于下。

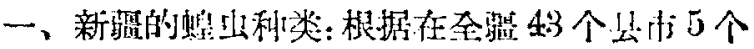

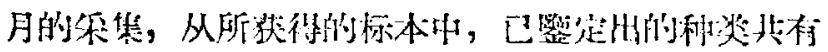

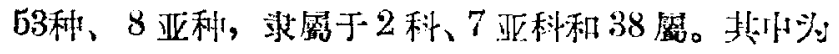

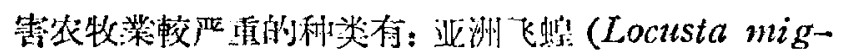
ratoria migratoria L.)、西伯利亚望（Gomphocerus sibiricus turkestanicus Mistshenko), 离火利

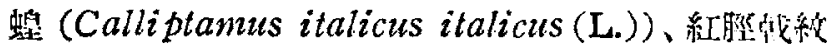
螅(Dociostaurus (s.) kraussi kraussi (Ingen))、 土克曼蛙 (Ramburiella turcomana (F.W.))、小. 热尖翅䗆 (Epacromitus legerstinus tergerstinus (Charp.)) 及科热蝊 (Duroniella angustata Mist-

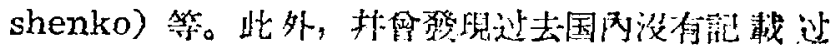

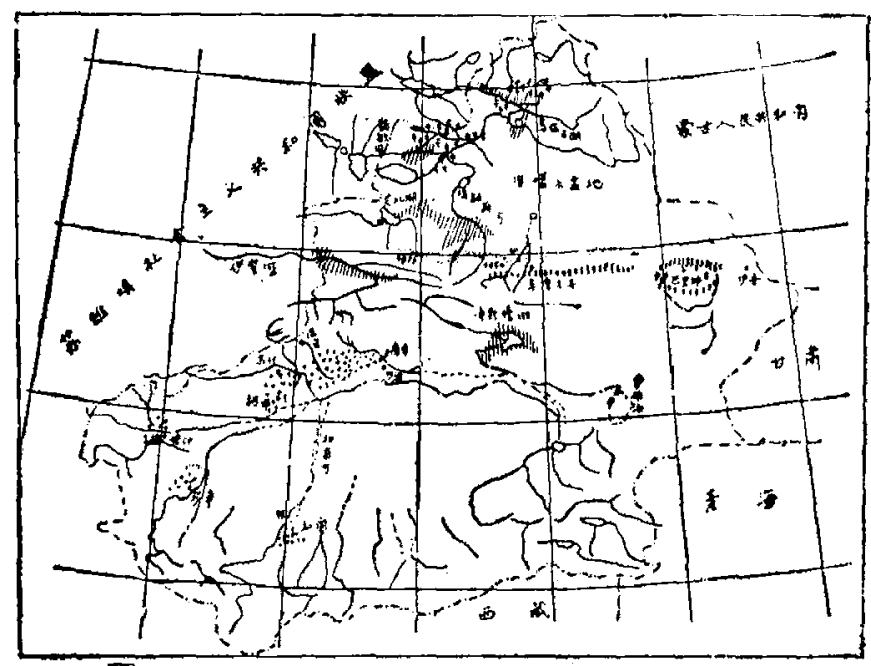

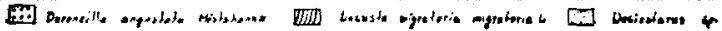

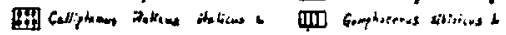

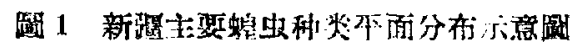

